\title{
A Transition Strategy from Fossil Fuels to Renewable Energy Sources in the Mexican Electricity System
}

\author{
Juan J. Vidal-Amaro ${ }^{* 1}$, Claudia Sheinbaum-Pardo ${ }^{2}$ \\ ${ }^{1}$ Instituto de Ingeniería, Universidad Nacional Autónoma de México, Edificio 12, Circuito Interior S/N, \\ UNAM-CU, C.P. 04510, Ciudad de México, México \\ e-mail: vidalamarojj@gmail.com \\ ${ }^{2}$ Instituto de Ingeniería, Universidad Nacional Autónoma de México, Edificio 12, Circuito Interior S/N, \\ UNAM-CU, C.P. 04510, Ciudad de México, México \\ e-mail: CSheinbaumP@iingen.unam.mx
}

Cite as: Vidal-Amaro, J. J., Sheinbaum-Pardo, C., A Transition Strategy from Fossil Fuels to Renewable Energy Sources in the Mexican Electricity System, J. sustain. dev. energy water environ. syst., 6(1), pp 47-66, 2018, DOI: http://dx.doi.org/10.13044/j.sdewes.d5.0170

\begin{abstract}
Renewable energy sources exploitation acquires special importance for creating low-carbon energy systems. In Mexico a national regulation limits the fossil fuel-based electricity generation to $65 \%, 60 \%$ and $50 \%$ by years 2024,2030 and 2050 respectively. This study evaluates several scenarios of renewables incorporation into the Mexican electricity system to attend those targets as well as a 75\% renewables-based electricity share target towards a $100 \%$ renewable system. By its size, the Mexican electricity system, with a generation of $260.4 \mathrm{TWh} /$ year ( $85 \%$ based on fossil fuels), can be regarded as an illustrating reference. The impact of increasing amounts of wind, photovoltaic solar, biomass, biogas, geothermal, hydro and concentrating solar power on the system's capacity to attend demand on a one-hour timescale resolution is investigated utilizing the EnergyPLAN model and the minimum total mix capacity method. Possible excess of electricity production is also assessed. For every target year, a solution is obtained corresponding to the combination resulting in the minimum total generation capacity for the electricity system. A transition strategy to a system with a high share of renewables-based electricity is designed where every transition step corresponds to the optimal energy mix for each of the target years.
\end{abstract}

\section{KEYWORDS}

Energy systems analyses, Sustainable energy supply, Energy transition, Renewable energies, Energy scenarios design, EnergyPLAN, Minimum total capacity mix model, Mexico.

\section{INTRODUCTION}

For several years, Mexico has been an energy self-sufficient country and a net energy exporter. In 2002, Mexico had the $9^{\text {th }}$ highest proved oil reserves in the world and the $22^{\text {th }}$ highest Natural Gas (NG) reserves [1]. However, a high oil production rate kept from 1997 until 2007 as well as an increasing NG production have led to a depletion in the proven oil and NG reserves as shown in Table 1.

\footnotetext{
${ }^{*}$ Corresponding author
} 
Also, the Mexican economic development has been strongly based on hydro-carbon intensive industry as indicated by a high energy intensity of 0.18 toe per thousand 2005 USD - compared to 0.15 for the US, 0.10 for Japan, 0.10 for Germany and 0.07 for Denmark [2] - combined with a Primary Energy Supply (PES) in Mexico which relies heavily on fossil fuels and with increasing demands. From 1990 to 2014 NG consumption increased by 53\%. In 2014 fossil fuels accounted for more than $91 \%$ of the PES [3], see Table 1.

Table 1. Characteristics of the energy matrix in Mexico

\begin{tabular}{|c|c|c|c|c|c|c|c|}
\hline \multirow{2}{*}{$\begin{array}{c}\text { Energy } \\
\text { source }\end{array}$} & \multicolumn{2}{|c|}{ National reserves } & \multicolumn{2}{|c|}{ PES 2014} & \multicolumn{3}{|c|}{ Installed capacity 2014} \\
\hline & 2002 & 2005 & {$[\mathrm{PJ}]$} & {$[\%]$} & Technology & [GW] & {$[\%]$} \\
\hline Naturnl & $702000 \mathrm{Mm}^{3}$ & $224154 \mathrm{Mm}^{3}$ & 201261 & 146 & Combined cycle & 23.3 & 35.6 \\
\hline INatura gas & $195,000 \mathrm{NIm}^{2}$ & $524,154 \mathrm{~N} 1 \mathrm{~m}$ & $5,045.01$ & 44.0 & $\begin{array}{l}\text { Gas turbine } \\
\text { Internal }\end{array}$ & 3.4 & 5.22 \\
\hline Oil & $25,425 \mathrm{Mb}$ & $9,711 \mathrm{Mb}$ & $3,505.06$ & 40.6 & $\begin{array}{l}\text { Combustion } \\
\text { Engine (ICE) }\end{array}$ & 1.31 & 2 \\
\hline Coal & - & - & 533.92 & 6.2 & $\begin{array}{l}\text { Condensing } \\
\text { Power Plants } \\
\text { (coal\&oil) }\end{array}$ & 18.33 & 28 \\
\hline Nuclear & - & - & 100.6 & 1.2 & $\begin{array}{c}\text { Nuclear } \\
\text { Hydro }\end{array}$ & $\begin{array}{c}1.4 \\
12.42\end{array}$ & $\begin{array}{c}2.13 \\
18.98\end{array}$ \\
\hline RES & - & - & 665.78 & 7.7 & $\begin{array}{c}\text { Geothermal } \\
\text { Wind }\end{array}$ & $\begin{array}{c}0.813 \\
2.03 \\
\end{array}$ & $\begin{array}{c}3.1 \\
1.24 \\
\end{array}$ \\
\hline & Total & & $8,624.26$ & 100 & & 65.45 & 100 \\
\hline
\end{tabular}

Furthermore, Mexico has the $14^{\text {th }}$ highest energy-related Greenhouse Gas (GHG) emissions in the world [4]. In 2012 these accounted for $67.3 \%$ of the national GHG emissions and came to a total of $503 \mathrm{Mt} \mathrm{CO}_{2}$ or a per capita emission of $3.7 \mathrm{t} \mathrm{CO}_{2}$ [5]. At the end of 2014 the installed capacity in Mexico came to $65.45 \mathrm{GW}$ of which technologies utilising fossil fuels accounted for more than 70\% [6] as shown in Table 1.

On the other hand, Mexico possesses important potentials for exploiting Renewable Energy Sources (RES). As widely documented by Vidal-Amaro et al. [7], Mexico can take advantage of several alternatives including: hydropower, bioenergy, solar radiation, geothermal power, wind power and wave power, nevertheless the last currently is not extensively studied. Table 2 shows the renewables potential documented in [7].

Table 2. Renewables potentials in Mexico

\begin{tabular}{|c|c|c|c|c|c|c|c|}
\hline \multirow[b]{2}{*}{$\begin{array}{l}\text { Hydro } \\
{\left[\mathrm{GW}_{\mathrm{e}}\right]}\end{array}$} & \multirow[b]{2}{*}{$\begin{array}{c}\text { Bioenergy } \\
{\left[\mathrm{GW}_{\mathrm{e}}\right]}\end{array}$} & \multirow[b]{2}{*}{$\begin{array}{c}\text { Solar } \\
\text { irradiance } \\
{\left[\mathrm{kWh} / \mathrm{m}^{2} \text { day }\right]}\end{array}$} & \multicolumn{2}{|c|}{ Geothermal } & \multicolumn{3}{|c|}{ Wind } \\
\hline & & & $\begin{array}{c}\text { Technical } \\
\text { feasibility } \\
{\left[\mathrm{GW}_{\mathrm{e}}\right]}\end{array}$ & $\begin{array}{c}\text { Probable } \\
\text { and possible } \\
{\left[\mathrm{GW}_{\mathrm{e}}\right]}\end{array}$ & $\begin{array}{c}\text { Capacity } \\
\text { factor } \\
>20 \% \\
{[\mathrm{GW}]}\end{array}$ & $\begin{array}{c}\text { Capacity } \\
\text { factor } \\
>30 \% \\
{[\mathrm{GW}]}\end{array}$ & $\begin{array}{c}\text { Capacity } \\
\text { factor } \\
>35 \% \\
{[\mathrm{GW}]}\end{array}$ \\
\hline 53 & $33-50$ & 5.5 & 4.6 & 7.2 & 71 & 11 & 5.2 \\
\hline
\end{tabular}

In 2008, the Mexican congress approved a legislation establishing limits in the use of fossil fuels for electricity generation of $65 \%$ by $2024,60 \%$ by 2035 and $50 \%$ by 2050 . Unfortunately, in December 2015 changes in a new bill approved by the current congress abolished these limits leading to unspecified targets for renewable energy sources in the electricity system and changing the original limits in the use of fossil fuels to participation objectives of "clean" energies, that include nuclear power and fossil fuels with carbon capture and storage technologies [8]. Yet defining a strategy for transitioning to a sustainable electricity system is important for Mexico in a context of rapid depletion 
of national fossil fuel reserves and continuous growth in energy consumption. Thus RES exploitation acquires a great importance for Mexico and its electricity system in order to maintain the current energy self-sufficiency and to decrease the national energy-related Carbon dioxide $\left(\mathrm{CO}_{2}\right)$ emissions.

\section{Scope and structure of the article}

The objective of this study is to design a strategy for transitioning from an electricity system highly based on fossil fuels to one based on renewable energy sources. This work is a second part of a series of studies aiming to present a scenario of $100 \%$ RES electricity system for Mexico. The fossil fuel limits established in the former 2008 energy law are used as the starting point to define the RES incorporation targets for the strategy. Hence a $35 \%$ RES electricity production share is established by $2024,40 \%$ of RES electricity is defined by 2035 , by 2050 the RES electricity share required is $50 \%$ and a target of $75 \%$ RES electricity share is established for subsequent years. The 2024 target was analyzed in a previous article [7], thus this study deals with the targets for the years 2035, 2050 and the $75 \%$ RES electricity share target.

Several scenarios of RES incorporation into the Mexican electricity system have been evaluated from a technical approach for each of the target years. To ensure that the system retains proper load-following capabilities, the technical feasibility of the scenarios is analyzed utilizing a simulation tool with high temporal resolution, making it possible to capture the fluctuations of the various RES as well as the inherent variations in the electricity demand. For every RES electricity target, a solution scenario is identified corresponding to the energy mix that is optimal in terms of the minimum total capacity that is necessary for the system. Therefore a clear energy transition strategy is obtained for the Mexican electricity system with specific RES capacity targets at defined years.

\section{Studies on the Mexican electricity system}

Islas et al. [9] conducted cost-benefit analyses of transition scenarios where RES account for up to $59 \%$ of the expected installed capacity by 2025 compared to business as usual scenarios for the Mexican electricity system. By taking into account several costs of energy production chain and a possible reduction in investment costs due to progress in technologies to exploit RES, they found a range of NG prices where transitional scenarios become economically attractive. A study on reduction of GHG emissions for the Mexican energy system conducted by Manzini et al. [10] evaluates a transition scenario where RES accounts for $31 \%$ of the total energy system and $43.5 \%$ of the installed power capacity by 2025 . The transition scenario stabilizes $\mathrm{CO}_{2}$ and methane emissions to 2.1 and 1.7 times higher than the 1995 emissions by 2025 .

A study published by the World Bank [11] evaluates several pathways to reduce GHG emissions in the end-use sectors and the energy production in Mexico until 2030. The study identifies a reduction potential of $876 \mathrm{Mt} \mathrm{CO}_{2}$ eq by adding 28,100 MW of RES capacity in the electricity sector compared to the official scenario, thus accounting for $48.4 \%$ of the total power by 2030. Oropeza-Perez et al. [12] evaluated the potential of natural ventilation in Mexico and its effects on the Mexican electricity system through energy system analyses. They found potential $\mathrm{CO}_{2}$ emission savings of $2.17 \%$ from the power generation emissions.

Vidal-Amaro et al. [7] developed an energy-mix optimization method that combines RES-potential estimations with simulations of technical feasibility analysis. They used the Minimum Total Mix Capacity (MTMC) method to evaluate several scenarios of RES incorporation in the Mexican electricity system to obtain capacity mixes of RES and fossil fuels that produce $35 \%$ of the annual electricity generation coming from RES by the year 2024. They identify optimal combinations of biomass, wind, Photovoltaic (PV) 
solar, hydro, geothermal and fossil fuels resulting in the minimum total installed capacity in the system that is necessary to properly supply demand and accomplish the target defined by 2024. Also, this was the first step in the development of a strategy for transitioning to a $100 \%$ RES electricity system in Mexico that is continued by the present work.

\section{MATERIALS AND METHODS}

To obtain the optimal RES integration scenarios in the Mexican electricity system for every target year, the MTMC method developed by Vidal-Amaro et al. [7] has been utilized to analyse scenarios for supplying 35\% of the electricity based on RES by 2024. As explained in [7], the MTMC method: "Identifies the optimal combination of energy sources that can satisfy the demand of an existing energy system when a minimum production of RES is specified or a limit on fossil fuels or nuclear power is established for a future date. The installed capacity for each energy source (renewable, fossil or nuclear) in the optimal mix configuration is obtained after an analysis of the system's response to the renewable power production introduced into the system. The inputs to the MTMC are capacity ranges of the RES to be integrated, whereas the outputs are complementary conventional power, RES electricity share and Excess of Electricity Production (EEP). The optimal mix configuration corresponds to the combination of RES and conventional power that makes the system achieve the limits defined with the minimum overall installed capacity".

The objective of the MTMC method is to minimize the total installed capacity in the system, hence the "optimal capacity mix" produced by this method regards to the combination resulting in the minimum total capacity required in the system that is capable of accomplishing the established targets. In this way, for every target year an objective scenario can be identified with a capacity mix of RES and conventional energy sources that produces the required RES electricity share and requires the minimum additions of power from the current situation. Then, by linking the optimal scenarios for every target year, a transition strategy can be developed with specific goals for RES-based capacities at defined dates.

To conduct the technical feasibility analyses of the scenarios, the MTMC method utilizes the EnergyPLAN model [13] which is a simulation tool with one-hour temporal resolution capacity. This makes possible scenario evaluations that take into account the fluctuations of the various RES as well as the inherent variations in electricity demand, looking for maintaining adequate load-following capabilities in the system. The EnergyPLAN model has been applied to evaluate a large number of cases on the energy field, and is widely acknowledged as an adequate analysis tool to help with the RES incorporation into energy systems. An exhaustive revision of the applications of EnergyPLAN can be found in [14] where Østergaard documented 95 different peer reviewed journal articles utilizing EnergyPLAN as far of May 2015 in areas including:

- Integration of RES in energy systems;

- High-RES scenarios;

- General methodological issues within energy systems modeling and simulation;

- Low-RES scenarios;

- Transport;

- District heating;

- The role of energy savings and the systems impacts;

- Life-cycle assessment;

- Grid stability;

- Transmission issues;

- Biomass usage; 
- Desalination;

- Waste as an energy source;

- Carbon capture and storage;

- PV;

- Market structures;

- Thermoelectric generators;

- Combined heat and power.

In the national scale, EnergyPLAN has been utilized in studies in Denmark, Ireland, Portugal, Macedonia, Jordan, Jiangsu, Italy, Croatia, Mexico, Finland, Britain, Serbia, Romania, Norway, Inner Mongolia, Hungary, Hong Kong, South Korea, Iran and Canada as Østergaard points out. A quick search in the Science Direct database reveals 19 new articles utilizing EnergyPLAN in 2016 and 7 articles since January 2017 as of March 2017, of which two new methods to optimize capacity combinations in energy systems can be found, in [15] EnergyPLAN is combined with a multi objective evolutionary algorithm, and a study that links EnergyPLAN with an external cost optimization computational tool is found in [16]. Also, a study on a continental scale can be found in [17] where a scenario of $100 \%$ RES system for Europe is developed, identifying the necessity of a smart energy system for the entire Europe as the way to achieve it.

\section{Steps of the minimum total mix capacity method}

For a detailed description of the MTMC it is recommended to consult Vidal-Amaro et al. [7]. A summary of the five steps of the method is shown below:

- Set the minimum RES-based energy share of the system;

- Acquire hourly production data for relevant RES and hourly demand profiles for a typical year;

- Establish different energy system scenarios with possible capacity ranges for every RES proposed for the system along with nuclear power or fossil fuels values from current system. RES ranges must be defined in accordance with previous evaluations of RES potentials, due to the fluctuating nature of RES, the scenarios built may not satisfy the demand at all times. This power deficit must be covered by additional dispatchable capacity or by electricity imports. When self-sufficiency is a condition for the system, dispatchable capacity is the only alternative, also, this additional capacity is one of the outputs of the method;

- Evaluate the scenarios using the EnergyPLAN model. Capacity values defining each scenario have to be input to EnergyPLAN for each scenario simulation. As RES are included as ranges, discrete values have to be chosen to conduct the corresponding calculation of RES share, power deficit and EEP. In this way, every range of RES is split into a number of representative capacity values, which can be chosen in accordance to a specific capacity-step of interest, such as $5 \mathrm{GW}$ or $10 \mathrm{GW}$, thus, for every scenario built in step 3, it is possible to obtain a clear picture of the system's response to the contributions of every RES. Power deficits calculated at this point reveal the magnitude of additional dispatchable capacity necessary to successfully integrate RES in each scenario, the power deficit in the MTMC is considered as additional conventional capacity. In this way, every scenario can be identified by the amount of RES power incorporated and by the complementary conventional capacity necessary to keep the system self-sufficient;

- Identify the combinations of RES and fossil fuels capacities that achieve the required RES share target with the minimum overall installed capacity for every scenario evaluated; 
Also, Vidal-Amaro et al. [7] explain that: "As several different RES integration scenarios may accomplish the same RES production target, the MTMC chooses the combination resulting in the minimum total installed capacity for the system, marking the optimal mix. However, as a number of the scenarios that accomplish the RES share target may result in near-optimal total capacities, this domain of scenarios can also be considered as alternatives that may later be analyzed from an economic point of view."

The MTMC method focuses on analyzing a system over different capacity ranges for the available RES. The system's simulation in EnergyPLAN requires specific capacity values, thus the RES capacity ranges are discretized and the analysis is conducted over all combinations resulting from the discretization. The RES investigated constitute the decision variables in the analysis while the optimization function is the total installed capacity in the system, which has to be minimal. The accuracy of the optimal solution is directly related to the discretization size, however it is evident that the effort and time required for performing the simulations increases rapidly with the number of intervals in the discretized range.

Efforts to eliminate researcher's iterative simulation work, resulting from the many combinations possible after the discretization in similar procedures, have been done leading to new frameworks for energy scenario analyses. The general idea is coupling EnergyPLAN with other external computational tools for performing the iterative task. The computational tools are programmed with the decision criteria and the specified constrains, it makes possible to analyze a larger number of combinations subject to the accomplishment of more than one objective at the same time.

In Mahbub et al. [15] a combination of a Multi Objective Evolutionary Algorithm (MOEA) and EnergyPLAN was performed and applied to a case study in the municipality of Aalborg, Denmark, aiming to obtain a 100\% RES-based energy system. The results obtained with the MOEA and EnergyPLAN were compared with the solution "manually" obtained in a previous study [18] showing that the "manual" configuration was not really the best alternative, nevertheless it was close to the optimal scenario obtained by the new approach. Also a number of other near-optimal solutions where found with better results than the manual one.

In Huang et al. [19], an iterative optimization procedure "manual procedure" for decreasing the flexibility gap after the incorporation of RES in the Serbian energy system was compared with the solutions found by the EPOPT [20] method that links EnergyPLAN with the GenOpt ${ }^{\circledR}$ software [21], an optimization program for the minimization of a cost function developed by the Berkeley Lab, The EPOPT method proved to be more effective than the manual procedure at finding the optimal configuration of minimum total cost for the Serbian energy system, the manual procedure was capable of finding solutions only in a costs range slightly higher than the optimal EPOPT configurations, and some of them not accomplishing with the specified constrains.

Both methods, EPOPT and MOEA-EnergyPLAN, are remarkable procedures that enhance the energy systems' optimization landscape and have shown excellent results. On the other hand, it could be interesting to compare the results obtained by these methods with the results obtained by the MTMC procedure utilized in this study, it is possible to think that the MTMC solutions be near-optimal configurations compared to the solutions obtained by the either of the two methods that link EnergyPLAN with other computational tools, as these allow an evaluation over a larger domain of possible configurations, still the MTMC method is capable to obtain a solution scenario constrained to two objectives at the same time, the first one is the accomplishment of a RES-based electricity production target in a self sufficient way, while the second is to obtain a capacity combination of minimum total installed capacity in the system. The precision of the solution can be improved by a refinement of the discretization size at the decision variables. 


\section{Evolution of the Mexican electricity system}

During the previous decade 2004-2014, the electricity consumption in Mexico grew at an average annual rate of 2.6\%, below of the official prognosis of 3.5\% [6]. In 2014 the Total Annual Electricity Consumption (TAEC) reached 301.46 TWh, 4,367 GWh (1.5\%) higher than in 2013, of the total $79.6 \%$ was produced by fossil fuels, $17.2 \%$ by RES and $3.2 \%$ by nuclear power [6]; the Maximum Electricity Demand (MED) in 2014 was $41.80 \mathrm{GW}$. According to official outlook [6], for the next 15 years the TAEC is expected to grow at an average rate of $3.5 \%$ while the MED is expected to grow at a rate of $4 \%$. Oropeza-Perez et al. [12] find a significant savings potential in e.g. cooling in Mexico. Nevertheless, despite consumption savings being of utmost importance for the future energy systems, no studies can be found that take into account all potential savings in the consumption sectors when presenting the outlook for the electricity system in Mexico. Therefore, in the scenarios building in this study, only the official projections of electricity demand are considered.

Hence, the electricity system for the first target year 2024 of the transition strategy would present a TAEC of 440.902 TWh, meanwhile the MED would reach 60.9 GW. The official forecast considers only a 15 -years time frame, thus the last year with an official prognosis for the Mexican electricity system is 2030. The target years 2035 and 2050 are beyond the time frame of the official outlook, however as official studies for the last ten years have considered growth rates for TAEC and MED of around 3.5\% and 4\% respectively, responding mainly to Gross Domestic Product (GDP) growth projections, in this study it is considered equal growth rates for TAEC and MED until 2050. In this way, by 2035 it would be necessary to attend a maximum demand of $85.45 \mathrm{GW}$ and an annual electricity consumption of 557.46 TWh. For the year 2050 the TAEC is of 933.9 TWh and the MED is $153.89 \mathrm{GW}$, nearly four times higher than current MED. This requires the addition of more than $85 \mathrm{GW}$ of capacity to the current electricity system plus an additional capacity as reserve. These values correspond to current installed capacity of electricity systems in countries like Canada (135 GW), Brazil (122 GW), France (129 GW) or Germany (177 GW), Russia (234 GW), India (255 GW), Japan (293 GW), on the other hand, the USA has an installed capacity of 1,063 GW while China has $1,174 \mathrm{GW}$ [2].

However, the growth of an electricity system to four times bigger than what currently is, represents a high challenge. Thus the question arises: how much can an electricity system be allowed to grow? One of the main problems related to such a big electricity system is the amount of related $\mathrm{CO}_{2}$ emissions, if RES are the solution to avoid fossil fuels consumption and $\mathrm{CO}_{2}$ emissions the main question turns into: how much of the electricity demand can be supplied by RES? In this way, it is proposed in this study that when defining a strategy for transitioning from an energy system highly based on fossil fuels to a system based solely on RES, the maximum demand allowed for the system must be limited in accordance with the maximum capacity coming from RES, that is possible to install based on the estimations of RES potentials. Hence, in a first investigation of a possible limit to the growth of maximum demand for the Mexican electricity system, this study selects the MED expected by 2050 as a possible limit, and evaluates several scenarios for supplying $75 \%$ of the electricity demand by capacity based on RES according to the RES potentials listed in the introduction.

\section{Construction of the scenarios for the years 2035, 2050 and the $75 \%$ renewable energy sources electricity scenario}

The analysis for the year 2024 (MED $=60.9 \mathrm{GW}$ and TAEC $=440.902 \mathrm{TWh}$ ) was developed in the previous study [7], where several scenarios of capacity incorporation based on biomass, biogas, wind and PV power were studied. The results revealed a 
domain of eleven different possible combinations of RES and fossil fuels capacity that make the system reach the target of 35\% RES electricity share with the minimum total installed capacity among all the possible combinations evaluated. These eleven combinations belong to three groups of scenarios, named "HighBio", "MidBio" and "LowBio", differentiated by distinct values of biomass capacity.

From this domain, the optimal mix in terms of the minimum total capacity required in the system resulted from the "HighBio" scenario where renewables account for nearly $40 \%(31.93 \mathrm{GW})$ of the total capacity, even though the participation of wind and PV power is rather insignificant as shown in Table 3.

Table 3. Combinations of minimum total capacity from scenarios by 2024 , with results obtained in [7]

\begin{tabular}{ccccc}
\hline Technology & Fuel & $\begin{array}{c}\text { 2024-HighBio } \\
{[\mathrm{GW}]}\end{array}$ & $\begin{array}{c}2024-\mathrm{MidBio} \\
{[\mathrm{GW}]}\end{array}$ & $\begin{array}{c}\text { 2024-LowBio } \\
{[\mathrm{GW}]}\end{array}$ \\
\hline & $\begin{array}{c}\text { Livestock Waste Biogas } \\
\text { (LWB) }\end{array}$ & 4.5 & 2 & 1 \\
Combined cycle & $\begin{array}{c}\text { Municipal Waste Biogas } \\
\text { (MWB) }\end{array}$ & 0.5 & 0.5 & 0 \\
& Natural gas & 36.623 & 35.3 & 36.185 \\
Nuclear & & 1.61 & 1.61 & 1.61 \\
& Fuel oil & 3.88 & 3.88 & 3.88 \\
Condensing Power & Coal & 2.6 & 2.6 & 2.6 \\
Plants (PP) & Coal/fuel oil & 2.778 & 2.778 & 2.778 \\
& Biomass & 6 & 4 & 2 \\
Geothermal & & 2.4 & 2.4 & 2.4 \\
Gas turbine & Natural gas & 0.693 & 0.693 & 0.693 \\
Hydro & & 16.532 & 16.532 & 16.532 \\
Wind & & 1 & 10 & 15 \\
PV solar & & 1 & 7 & 10 \\
\hline Total & & 80.116 & 89.293 & 94.678 \\
\hline
\end{tabular}

Within the "MidBio" scenario, the combination of minimum total capacity resulted in a more diversified mix in which the RES-based capacity represents $47.5 \%$ (42.43 GW) of the total, finally, within the "LowBio" scenario the combination with the minimum total capacity corresponded to a mix where RES-based capacity accounts for $50.62 \%$ $(47.932 \mathrm{GW})$ of the total capacity as shown in Table 3.

\section{Scenarios of $40 \%$ renewable energy sources electricity share by 2035}

By 2035 the expected MED is 85.45 MW and the TAEC is 557.46 TWh. With the scenarios for year 2024 the RES share target achieved is $35 \%$, these combinations are the basis for building scenarios for the year 2035 .

Table 4 shows the three scenarios for 2035; bioenergy has been included with three different capacities, hence becoming the decision variable basis for building the scenarios named 2035-LowBio, 2035-MidBio and 2035-HighBio. For the 2035-LowBio the bio capacity is $8.5 \mathrm{GW}$, in the 2035-MidBio the bio capacity is $11 \mathrm{GW}$ and for the 2035-HighBio the bio capacity is $12.6 \mathrm{GW}$. All three keep the same capacity based on nuclear and fossil fuels as well as geothermal and hydro power. Within every scenario, the impact of increasing amounts of wind and PV power is evaluated an thus listed as ranges, for wind power the range is 5-40 GW whereas for PV power is 5-50 GW.

As the actual minimum necessary Natural Gas Combined Cycles (NG-CC) capacity is one of the results of the analysis following the MTMC method, the NG-CC capacity listed in the 2035 scenarios is shown solely as a reference, indicating a value higher than 
the corresponding capacity of the optimal scenarios for 2024. The capacity of coal and fuel oil based technologies has been reduced 50\% with regard to their values in the 2024 scenarios according to a retirement plan taking into account power plant's lifetime. On the other hand, hydro and geothermal power keep the same capacity as in the 2024 scenarios as their maximum feasible potentials are exploited.

Table 4. Scenarios for years 2035, 2050 and for 75\% RES electricity share

\begin{tabular}{cccccccc}
\hline Technology & Fuel & $\begin{array}{c}2035 \\
\text { LowBio } \\
{[\mathrm{GW}]}\end{array}$ & $\begin{array}{c}2035 \\
\text { MidBio } \\
{[\mathrm{GW}]}\end{array}$ & $\begin{array}{c}2035 \\
\text { HighBio } \\
{[\mathrm{GW}]}\end{array}$ & $\begin{array}{c}2050 \\
\text { LowBio } \\
{[\mathrm{GW}]}\end{array}$ & $\begin{array}{c}2050 \\
\text { HighBio } \\
{[\mathrm{GW}]}\end{array}$ & $\begin{array}{c}75 \% \text { RES } \\
\text { share } \\
{[\mathrm{GW}]}\end{array}$ \\
\hline $\begin{array}{c}\text { Livestock Waste } \\
\text { Biogas (LWB) } \\
\text { combined }\end{array}$ & 4 & 4.5 & 6 & 8 & 12 & 14 \\
& $\begin{array}{c}\text { Municipal Waste } \\
\text { Biogas (MWB) }\end{array}$ & 0.5 & 0.5 & 0.6 & 0.8 & 1 & 1.4 \\
& Natural gas & $>35.3$ & $>35.3$ & $>35.3$ & $>50$ & $>50$ & $>50$ \\
\hline Nuclear & & 1.6 & 1.6 & 1.6 & 1.6 & 1.6 & 1.6 \\
\hline Condensing & Fuel oil & 1.9 & 1.9 & 1.9 & 0.5 & 0.5 & 0 \\
Power Plant & Coal & 1.3 & 1.3 & 1.3 & 1 & 1 & 0 \\
(PP) & Coal/fuel oil & 1.4 & 1.4 & 1.4 & 0.5 & 0.5 & 0 \\
\hline Geothermal & Biomass & 4 & 6 & 6 & 6 & 8 & 15 \\
Gas turbine & Natural gas & 0.3 & 0.3 & 0.3 & 0.2 & 0.2 & 0 \\
Hydro & & 16.5 & 16.5 & 16.5 & 16.5 & 16.5 & 16.5 \\
CSP solar & & 0 & 0 & 0 & 10 & 10 & 25 \\
Wind & & $5-40$ & $5-40$ & $5-40$ & $20-60$ & $20-60$ & $40-90$ \\
PV solar & & $5-50$ & $5-50$ & $5-50$ & $20-60$ & $20-60$ & $40-70$ \\
Total & & $79.3-159.3$ & $81.8-161.8$ & $83.4-173.4$ & $137.8-217.8$ & $144-224$ & $205.9-265.9$ \\
\hline
\end{tabular}

\section{Scenarios of 50\% renewable energy sources electricity share by 2050}

The expected MED by 2050 is 933.9 TWh and the MED is 153.89 GW. Two scenarios have been built to supply $50 \%$ of the electricity demand with RES. As shown in Table 4, in the 2050-LowBio scenario a capacity of $14.8 \mathrm{GW}$ based on bioenergy has been included, on the other hand, in the 2050-HighBio scenario this capacity accounts for $21 \mathrm{GW}$. Coal and fuel oil power plants keep a total capacity of $2 \mathrm{GW}$, this capacity corresponds to the last power plants running on these fuels and it is expected to be switched off or converted to biomass in the subsequent years. On the other hand, the actual NG-CC capacity is obtained as a result of the analysis using the MTMC method, thus the capacity of these listed in Table 4 is indicated solely as a reference. Hydro and geothermal power exploit their maximum potentials, while the impact of increasing amounts of wind and PV power is evaluated, thus their capacities are listed as ranges from $20 \mathrm{GW}$ to $60 \mathrm{GW}$ in Table 4. Also $10 \mathrm{GW}$ of Concentrating Solar Power (CSP) technologies are included in both 2050 scenarios.

\section{The $75 \%$ renewable energy sources electricity share scenario}

An implicit question in the design of a $100 \%$ renewable energy system is that of how much can the energy system be let to grow, a pertinent answer is: "as much as RES can support". Thus for the Mexican electricity system a first exploration of this possible limit is realized by the analysis of a scenario where $75 \%$ of the electricity demand is attended by RES. We decided to test the values by 2050 of TAEC (933.9 TWh) and MED $(153.89 \mathrm{GW})$ as a possible limit to the size of the Mexican electricity system, considering that such demand corresponds to a system nearly four times bigger than what currently exists in Mexico. Therefore, the $75 \%$ RES electricity share scenario is designed for attending a demand equal to that expected by 2050 . The scenario includes the maximum 
potentials of biogas from municipal and livestock waste and of biomass from agricultural waste in Mexico, these potentials account for $30.4 \mathrm{GW}$ as listed in Table 4, also a high contribution form CSP technology is considered with the addition of $25 \mathrm{GW}$ of capacity. The only contribution from fossil fuels corresponds to NG-CC whose actual capacity has to be obtained as a result of the evaluation following the MTMC method. In the same way as with the previous scenarios, hydro and geothermal power are included with their maximum potentials, and the impact of increasing amounts of wind and PV power is evaluated, thus their capacity ranges are from $40 \mathrm{GW}$ to $90 \mathrm{GW}$ and from $40 \mathrm{GW}$ to $70 \mathrm{GW}$ respectively in Table 4 . The time when this scenario has to be implemented is not defined, yet it should be past 2050 .

\section{RESULTS}

The analysis of the scenarios is realized following the MTMC method as described in section "Materials and methods" and utilizing the EnergyPLAN model for the system simulations. Curves of hourly data for electricity demand, geothermal and hydro electricity production, wind production, and solar irradiance for PV electricity production utilized in the analyses were developed in the previous study [7]. On the other hand, Figure 1 shows the hourly CSP electricity production curve utilized in the analyses and developed to attend the hours of higher demand in Mexico.

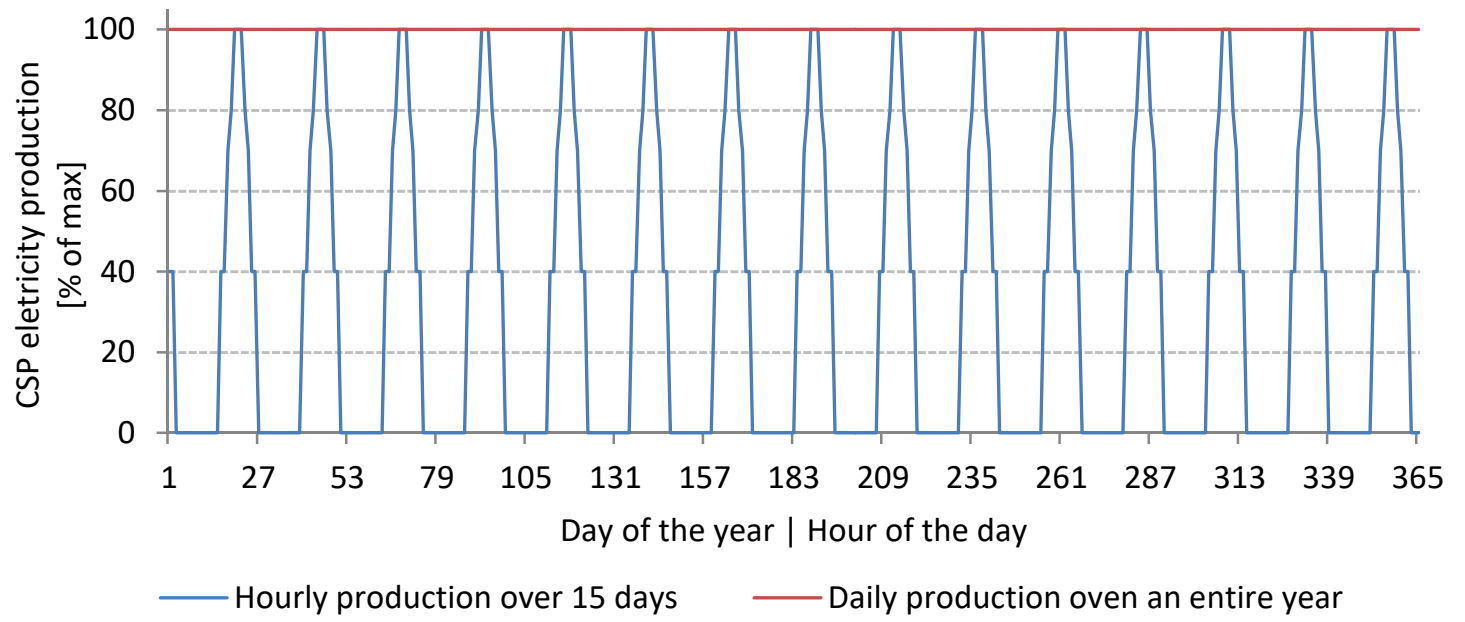

Figure 1. CSP hourly and daily electricity production, normalized values where 100 is the peak hourly/daily production

Concentrating solar power technologies possess some advantages regarding dispatch schemes. The ability to incorporate thermal storage devises to concentrating systems makes possible to delay the start-up of the electricity generator for up to 15 hours [22]. Also, different generator capacities can use the stored thermal energy in different ways, for instance, a generator with a high capacity will consume all the thermal energy in a shorter time than a generator of lower capacity. Hence, a CSP plant can be designed to operate as a base load power plant, as an intermediate load power plant or as a peak-load power plant [23]. Also, examples of hybrid power plants combining CSP with biomass have been explored [24].

\section{Annual renewable energy sources electricity share}

Renewable energy sources share for 2035 scenarios. Figure 2 shows the annual RES electricity shares for the 2035-HighBio, 2035-MidBio and 2035-LowBio scenarios, each 
line corresponds to a fixed wind capacity while PV increases. The 40\% RES share target can be achieved with different Wind-PV combinations from the three 2035 scenarios.

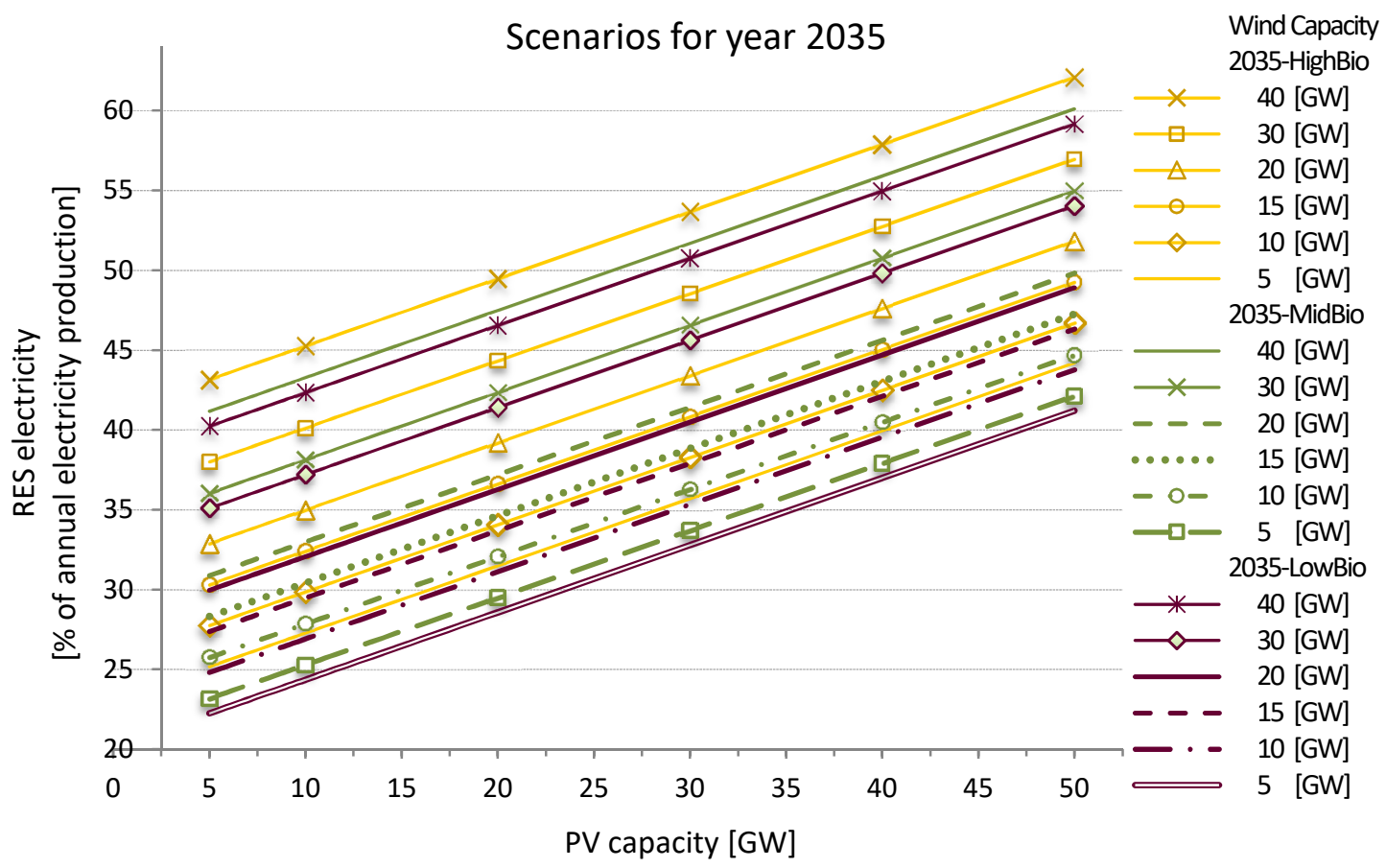

Figure 2. RES electricity share for 2035 scenarios, the analyses use 2004 wind data, low wind production year

For a defined wind capacity a minimum PV power that makes possible to produce $40 \%$ of RES electricity share can be identified. The corresponding PV power is reduced when wind capacity increases. RES electricity share values are increased with higher bioenergy-power values, hence for equal wind-PV combinations, RES electricity shares in 2035-HighBio scenario are higher than those corresponding to 2035-MidBio and 2035-LowBio. Every wind capacity evaluated in the three 2035 scenarios produces $40 \%$ of RES electricity with a corresponding PV within the range analysed, also RES electricity shares higher than $40 \%$ can be obtained with some wind-PV combinations.

Every wind-PV combination that produces the $40 \%$ RES electricity share can be considered as an alternative, thus a large domain of possible solutions is created, nevertheless, only few combinations from this domain can lead to minimum values of total installed capacity in the system, depending on the required amount of complementary dispatchable capacity.

Renewable energy sources share for 2050 scenarios. Figure 3 shows the RES electricity share for the 2050 scenarios. As in 2035 scenarios, the impact that bioenergy has on increasing RES shares is confirmed. From all the wind-PV ranges explored, only $40 \mathrm{GW}$ of wind capacity within the 2050-LowBio scenario does not reach the 2050 target. Also a domain of possible solutions of wind-PV combinations from both scenarios producing $50 \%$ of RES electricityis identified.

The scenario of $75 \%$ renewable energy sources electricity share. As mentioned in previous sections, the projected electricity demand for 2050 corresponds to an electricity system nearly four times bigger than what currently exists in Mexico. This large electricity system has been chosen to investigate the possibilities of supplying $75 \%$ or more of the electricity demand based on RES. As shown in Figure 3, only wind capacities 
higher than $80 \mathrm{GW}$ can produce $75 \%$ of RES electricity or more depending on the PV capacity added to the system. Also, for this scenario a RES share slightly higher than $85 \%$ can be produced with the highest wind-PV combination evaluated, that is $110 \mathrm{GW}$ of wind capacity and $90 \mathrm{GW}$ of PV power.

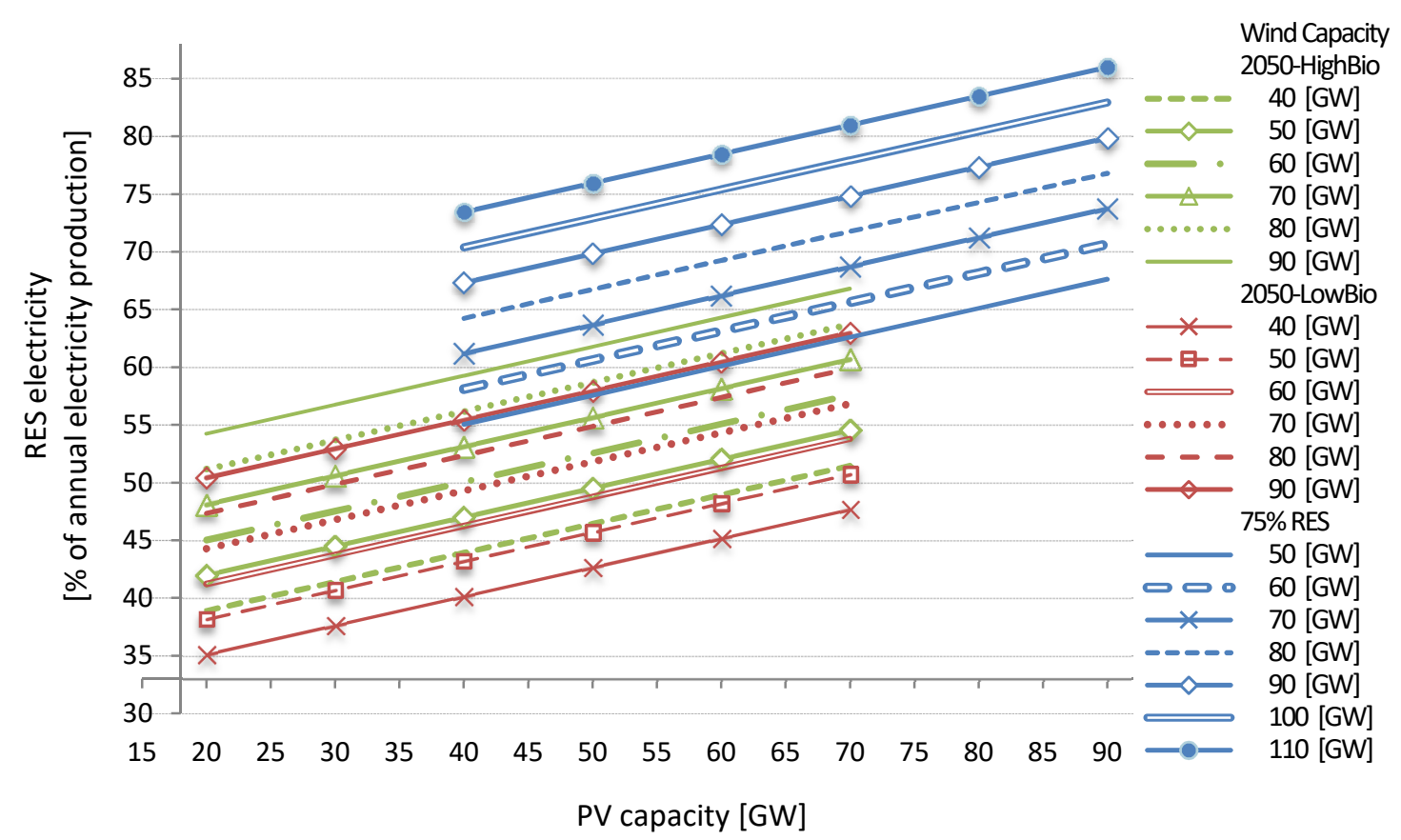

Figure 3. RES electricity share for the 2050 scenarios and the $75 \%$ RES share scenario, the analyses use 2004 data, low wind production year

\section{Minimum necessary capacity on natural gas combined cycles}

Due to capacities on hydro, geothermal, biomass, nuclear, coal and fuel oil have been fixed in each scenario before knowing the system's performance, and due to wind and PV power are fluctuating RES, the system can face power deficits during some hours throughout the year even with the wind-PV combinations that reach the objectives settled for the target years. The size of the highest difference at any hour during the year between electricity demand and production of all the energy sources in the scenarios is the amount of additional dispatchable capacity that is required in the system. NG-CC is the technology chosen as the additional dispatchable capacity, which should be minimized as it presents a backup cost. For the calculation of the minimum necessary dispatchable capacity, the scenarios' simulations were realized with no contribution from NG-CC, thus the maximum calculated difference between demand and supply corresponds to the minimum necessary capacity on NG-CC.

Minimum natural gas combined cycles for 2035. Figure 4 shows the minimum NG-CC necessary for the 2035 scenarios. For the 2035-LowBio scenario the required NG-CC capacity is in the range of $56.6 \mathrm{GW}$ to $46.2 \mathrm{GW}$ depending on the specific wind-PV combination, for the 2035-MidBio the range is between $54.1 \mathrm{GW}$ and 43.78 $\mathrm{GW}$ and for the 2035-HighBio the required capacity is between $52.5 \mathrm{GW}$ and $42.2 \mathrm{GW}$.

It is clear the impact that bioenergy has on the NG-CC required capacity, the higher bioenergy capacity the lower NG-CC requirements. Figure 4 also reveals that PV power highly contributes to drastic reductions of NG-CC requirements in the gap 5-20 GW of PV capacity, after that, the curves show an asymptotic behaviour, hence the addition of PV capacity further $20 \mathrm{GW}$ has only smaller impacts on reducing NG-CC requirements in all three 2035 scenarios. 


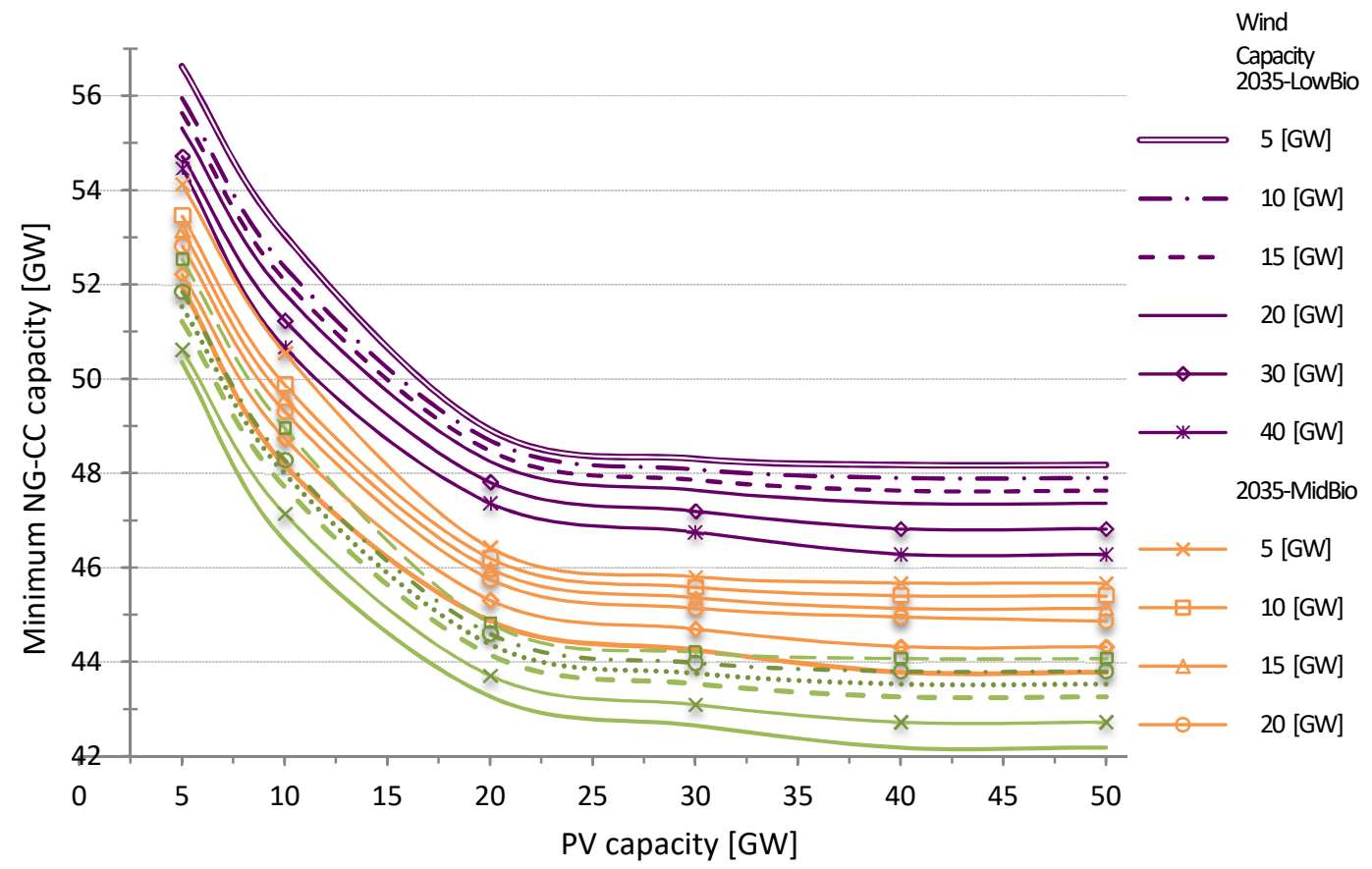

Figure 4. Minimum NG-CC capacity for the 2035 scenarios, simulations utilizing 2004 wind data, low wind production year

Minimum natural gas combined cycles for 2050. For the 2050 scenarios, bioenergy power has the highest impact on reducing NG-CC requirements. As shown in Figure 5, values from the 2050-LowBio scenario which are in the range of $91.6 \mathrm{GW}$ to $85.2 \mathrm{GW}$ are approximately $7 \%$ higher than values from 2050-HighBio. In the 2050 scenarios PV power has lower effectiveness on reducing NG-CC needs than in 2035 scenarios, nevertheless it is still possible to obtain reductions of up to $3 \mathrm{GW}$ of $\mathrm{NG-CC}$ for a defined wind capacity curve by increasing PV power.

Curve in Figure 5 reflects the combined generation of different CSP plants, some of which operate as base-load plants, some as intermediate-load plants and some others as peak-load plants.

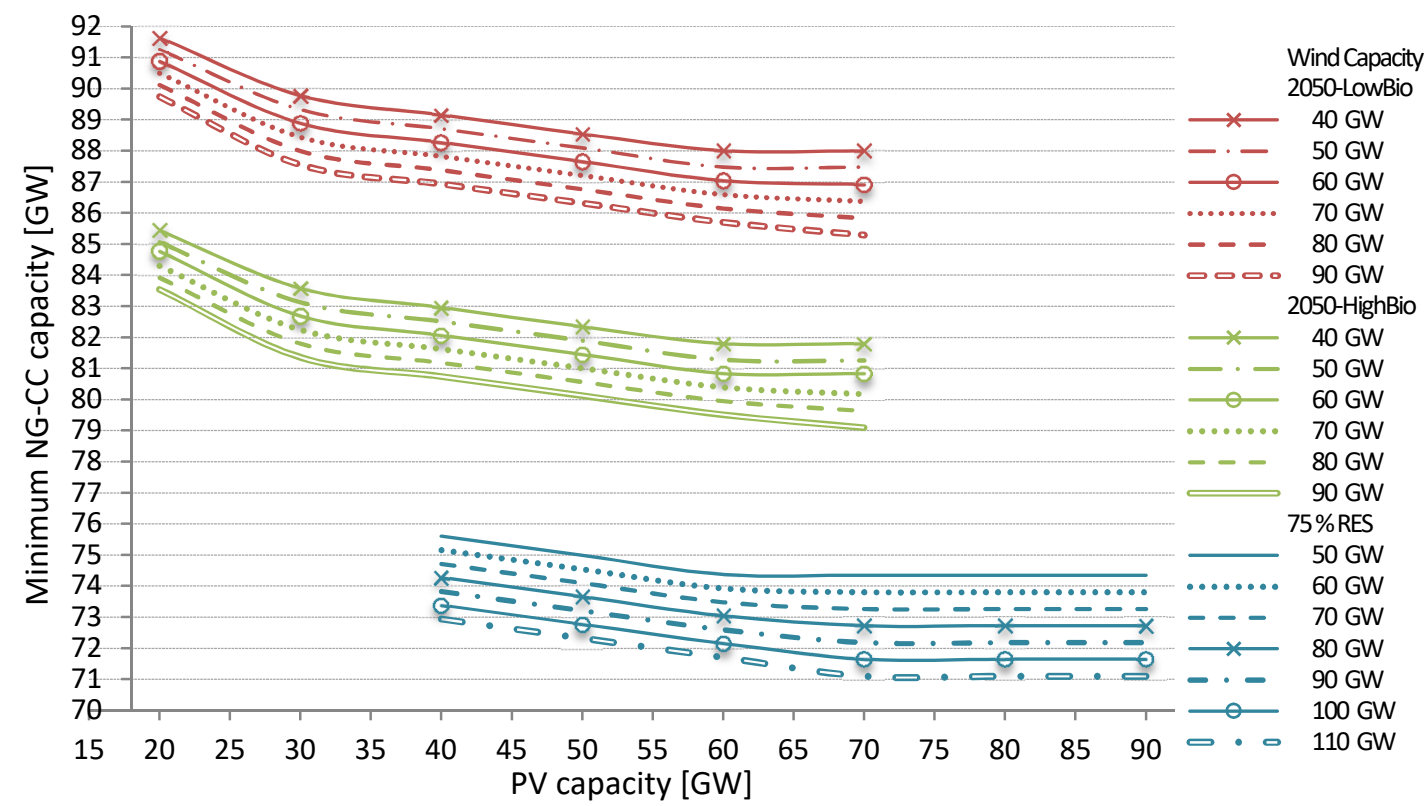

Figure 5. Minimum NG-CC capacity for the 2050 scenarios and the $75 \%$ RES share scenario, simulations utilizing 2004 wind data, low wind production year 
Minimum natural gas combined cycles for the $75 \%$ renewable energy sources scenario. In the $75 \%$ RES scenario, the required NG-CC capacities are in the range of $75.5 \mathrm{GW}$ to $71 \mathrm{GW}$ as shown in Figure 5. For a fixed wind capacity, PV power can contribute in reducing up to $2 \mathrm{GW}$ of $\mathrm{NG}-\mathrm{CC}$ requirements. The asymptotic behaviour presents earlier for lower wind capacities. This phenomenon is also present in the corresponding NG-CC graphs for the 2035 and 2050 scenarios.

The higher the wind capacity installed in the system, the later the NG-CC curve becomes asymptotic. For this scenario, as well as for the 2050 scenarios, it can be expected that the domain of near-optimal capacity combinations be integrated by configurations very similar in terms of the overall installed capacity in the system, even though the specific combination of Bio-Wind-PV be different.

\section{Optimal capacity combinations for the target years}

As seen in Figures 2 and 3, every target of RES electricity share can be reached with different combinations of Bio, Wind and PV (BWPV) capacities, which form a domain of possible solutions for the electricity system. For 2035 this domain is integrated by sixteen different BWPV combinations that produce $40 \%$ of RES electricity, for 2050 nine BWPV combinations reach the 50\% RES share target, meanwhile for the $75 \%$ RES scenario a domain of four different BWPV combinations produce the required RES electricity share. However, as seen in Figures 4 and 5, every BWPV combination requires a minimum complementary NG-CC capacity to avoid production deficits. Therefore each BWPV combination results in a different total installed capacity in the electricity system.

Total installed capacities for the domain of possible solutions by 2035 are in the ranges of $134.33 \mathrm{GW}$ to $129.64 \mathrm{GW}$ for the 2035-LowBio scenario, $132.12 \mathrm{GW}$ to $128.17 \mathrm{GW}$ for the 2035-MidBio scenario and $129.88 \mathrm{GW}$ to $124.07 \mathrm{GW}$ for the 2035-HighBio scenario as shown in Figure 6, where each dot corresponds to the total installed capacity for the possible solution identified by the wind capacity shown in the abscissa and the corresponding PV capacity, not shown in Figure 6, that makes the system reach a $40 \%$ RES-electricity share as shown in Figure 2.

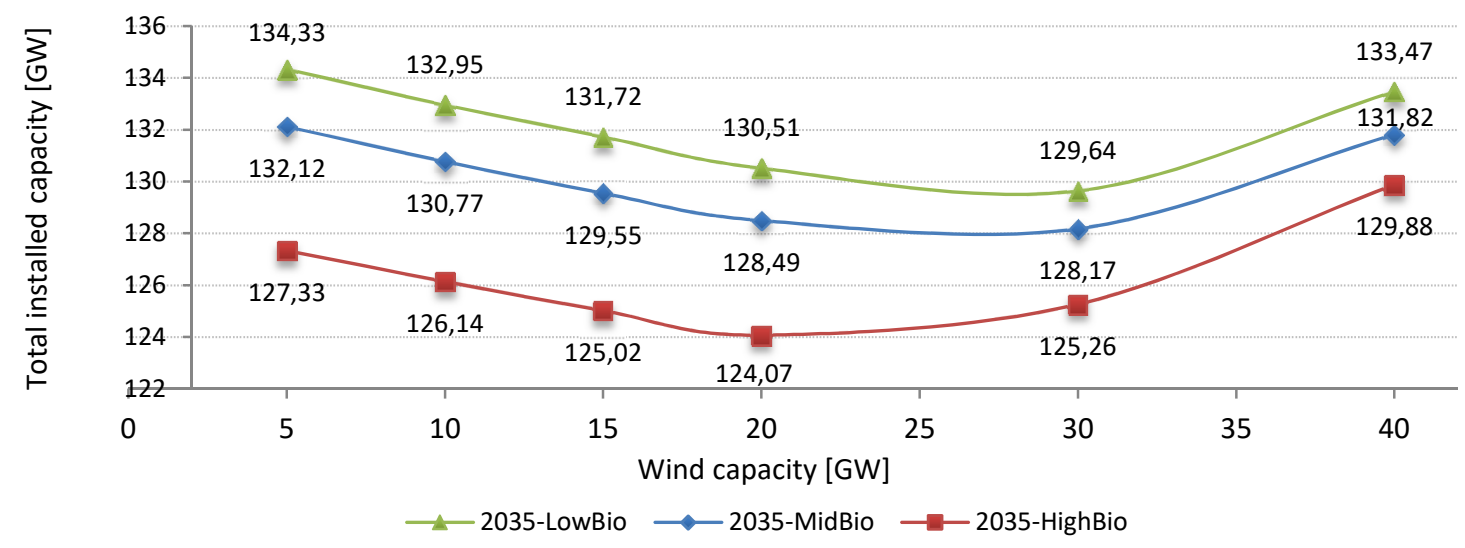

Figure 6. Total installed capacity for the domain of possible solutions in the 2035 scenarios

Curves of total installed capacity for the domain of possible solutions by 2050 and the $75 \%$ RES scenario can also be constructed showing similar qualitative results, however they are not presented in order to save space, the total capacity ranges in the 2050 possible solutions domain are $252.5 \mathrm{GW}$ to $246.4 \mathrm{GW}$ for the 2050-LowBio scenario and $240 \mathrm{GW}$ to $234.3 \mathrm{GW}$ for the 2050 -HighBio scenario. For the $75 \%$ RES scenario the total capacity range is $297 \mathrm{GW}$ to $298.3 \mathrm{GW}$.

As explained in "Materials and methods" section, the optimal energy mix corresponds to the combination that reaches the defined RES electricity share target and 
results in the minimum total installed capacity in the system for the target year. Table 5 shows the BWPV and NG-CC capacity mixes resulting in the minimum total capacity from the domains of possible solutions for every scenario evaluated.

Table 5. Combinations resulting in a minimum total installed capacity for every scenario, remaining power includes nuclear, geothermal, hydro and non NG-CC thermal power plants as shown in Table 4

\begin{tabular}{ccccccc}
\hline Scenario & $\begin{array}{c}\text { Bio } \\
{[\mathrm{GW}]}\end{array}$ & $\begin{array}{c}\text { Wind } \\
{[\mathrm{GW}]}\end{array}$ & $\begin{array}{c}\text { PV } \\
{[\mathrm{GW}]}\end{array}$ & $\begin{array}{c}\text { NG-CC } \\
{[\mathrm{GW}]}\end{array}$ & $\begin{array}{c}\text { Remaining } \\
\text { power [GW] }\end{array}$ & $\begin{array}{c}\text { Total } \\
{[\mathrm{GW}]}\end{array}$ \\
\hline 2035-LowBio & 8.5 & 30 & 16.67 & 48.95 & & 129.64 \\
2035-MidBio & 11.0 & 30 & 14.44 & 47.22 & 25.52 & 128.17 \\
2035-HighBio & 12.6 & 20 & 21.91 & 44.04 & & 124.07 \\
2050-LowBio & 14.8 & 80 & 30.56 & 87.96 & 33.00 & 246.35 \\
2050-HighBio & 21.0 & 70 & 27.56 & 82.74 & & 234.33 \\
75\% RES & 30.4 & 100 & 40.00 & 73.38 & 45.50 & 289.32 \\
\hline
\end{tabular}

By 2035 the optimal energy mix is obtained from the 2035-HighBio scenario with a bio capacity of $12.6 \mathrm{GW}$, a wind capacity of $20 \mathrm{GW}$ and $21.91 \mathrm{GW}$ of PV power, the total installed capacity for this energy mix is $124.07 \mathrm{GW}$. By 2050 the optimal combination results from the 2050-HighBio scenario with a wind capacity of $70 \mathrm{GW}$ and $27.56 \mathrm{GW}$ of PV power with a total capacity of $234.33 \mathrm{GW}$. Finally, the energy mix of minimal total capacity for the $75 \%$ RES scenario is obtained with $100 \mathrm{GW}$ of wind capacity, $40 \mathrm{GW}$ of PV power, $30.4 \mathrm{GW}$ of bio-power and $74.38 \mathrm{GW}$ of NG-CC.

\section{Transition strategy for the Mexican electricity system}

Given the national energy transition goals established by years 2024, 2035 and 2050 mandated in the energy bill approved in Mexico in 2014 [8], the transition strategy shown in Figure 7 is created, this strategy allows the current Mexican electricity system highly based on fossil fuels to turn into an electricity system that supplies $75 \%$ of the electricity demand by RES, this transition strategy is built by taking the optimal combinations obtained from the scenarios created by years 2024, 2035 and 2050. In every transition stage, each technology/energy-source capacity is clearly identified and corresponds to the combination of minimum total installed capacity for every target year.

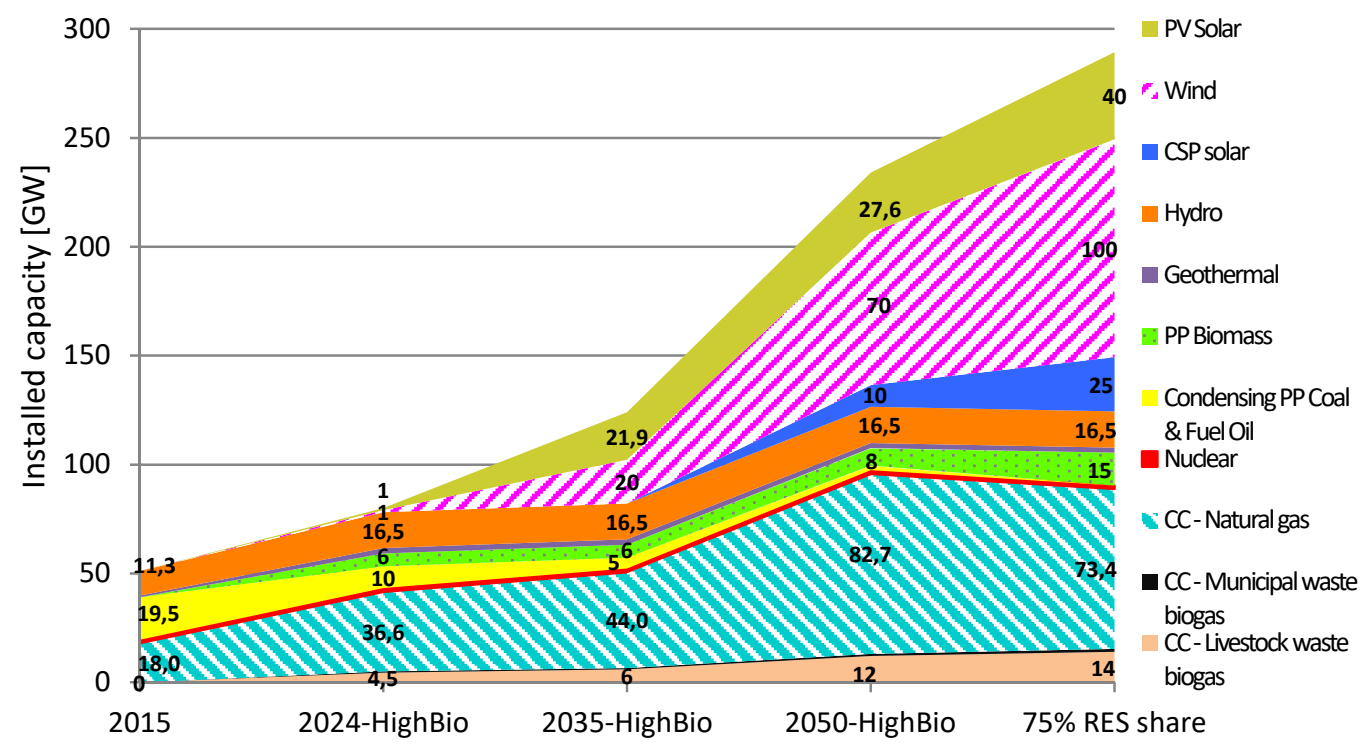

Figure 7. Evolution of the installed capacity by technology for the Mexican electricity system, values form 2024-HighBio were obtained in the previous study [7] 
On the other hand, it is clear that the required installed capacity in the $75 \%$ RES scenario is nearly five times higher than the current installed capacity in the Mexican electricity system. Despite Mexico possessing a large potential of RES that makes possible the existence of such electricity system, it necessarily implies the use of a large land extension. The required wind capacity is close to the assessed wind potential for capacity factors higher than $20 \%$, located in a total area of $15,000 \mathrm{~km}^{2}$ [25]. Land required for PV power would be between $200 \mathrm{~km}^{2}$ and $360 \mathrm{~km}^{2}$ for a PV land use of $5-9 \mathrm{~km}^{2} / \mathrm{GW}$ [26]. Current CSP projects around the world report a land use of $5 \mathrm{~km}^{2} / \mathrm{GW}$ to $10 \mathrm{~km}^{2} / \mathrm{GW}$ [27] which means that the land use for the required CSP capacity is of between $125 \mathrm{~km}^{2}$ and $250 \mathrm{~km}^{2}$.

Moreover, the capacity required for NG-CC implies a large consumption of a non-renewable energy source. For obtaining an electricity system $100 \%$ based on RES, it would be necessary to replace $73.4 \mathrm{GW}$ of NG-CC by a renewable and dispatchable energy source, such as CSP or biomass, scenario that looks hard to achieve. Therefore choosing the projected demand by 2050 as the possible limit to the size of the Mexican electricity system towards a $100 \%$ based electricity share presents some difficulties hard to overcome. Hence this result points towards the limitation of the electricity-system's growth at a value lower than the 2050's projected demand.

\section{Excess of electricity production}

Problems of electricity excess can appear to be caused by high levels of electricity production from variable RES, such as wind or PV power, exceeding the electricity demand during some moments. This possible EEP can overcharge the system, thus it must be quantified and some strategies have to be implemented to avoid this problem. To evaluate the magnitude of the EEP that can occur in the system, the calculations were conducted utilizing the total capacity of wind and PV power at any moment in all the calculations. Production form variable RES is given priority while storable fuels (such as fossil fuels, hydro or biomass) are utilized only when still required for covering demand. However a minimum of $30 \%$ of electricity production coming from units with voltage and frequency control capabilities is established at any time.

Excess of electricity production for 2035 scenarios. Figure 7 shows the EEP for the scenarios by year 2035. The only difference between the 2035 LowBio, MidBio and HighBio scenarios corresponds to the amount of installed bioenergy power, which is given a second priority of usage, therefore EEP caused by wind and PV power is the same in all three scenarios. As seen in Figure 8, the 2035 optimal capacity mix (wind $=20 \mathrm{GW}, \mathrm{PV}=21.9 \mathrm{GW}$ ) listed in Table 5 does not present excess electricity production.

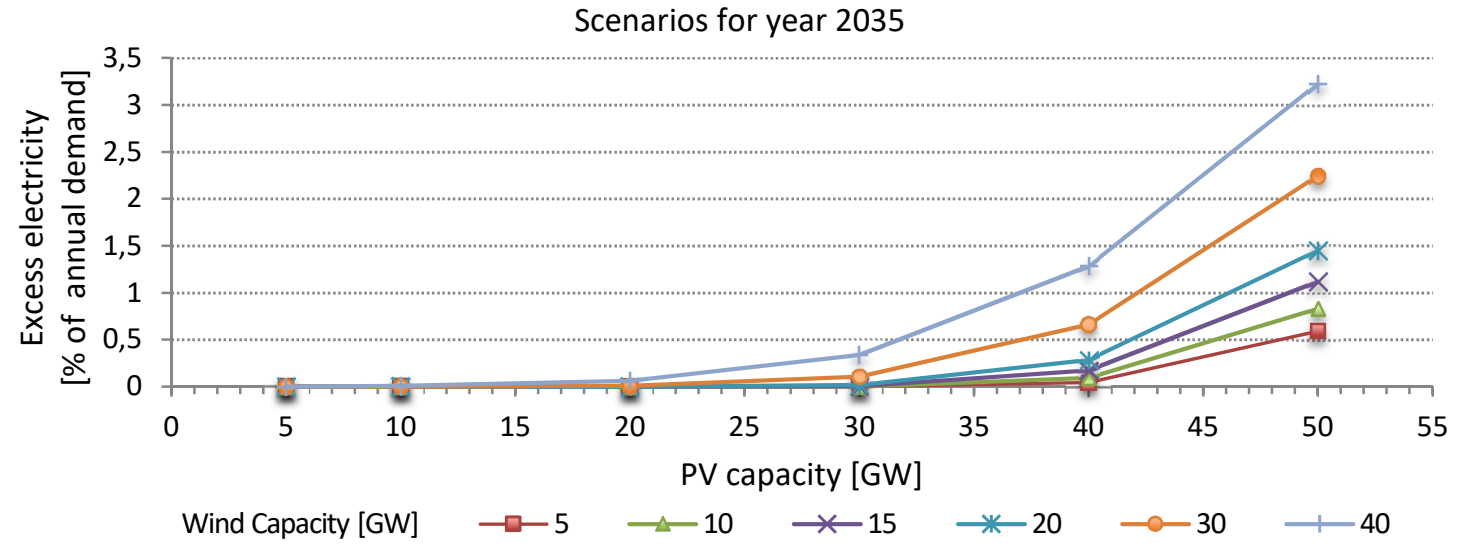

Figure 8. Excess of electricity production for 2035 scenarios 
Excess of electricity production for 2050 scenarios. Figure 9 shows the EEP for the 2050 scenarios. The combination of minimum total installed capacity from the 2050-LowBio scenario (wind $=80 \mathrm{GW}, \mathrm{PV}=30.56 \mathrm{GW}$ ) presents a negligible amount of EEP (0.19\%), meanwhile, the optimal energy mix from 2050-HighBio (wind $=70 \mathrm{GW}$, $\mathrm{PV}=27.56 \mathrm{GW}$ ) do not produce excess electricity.

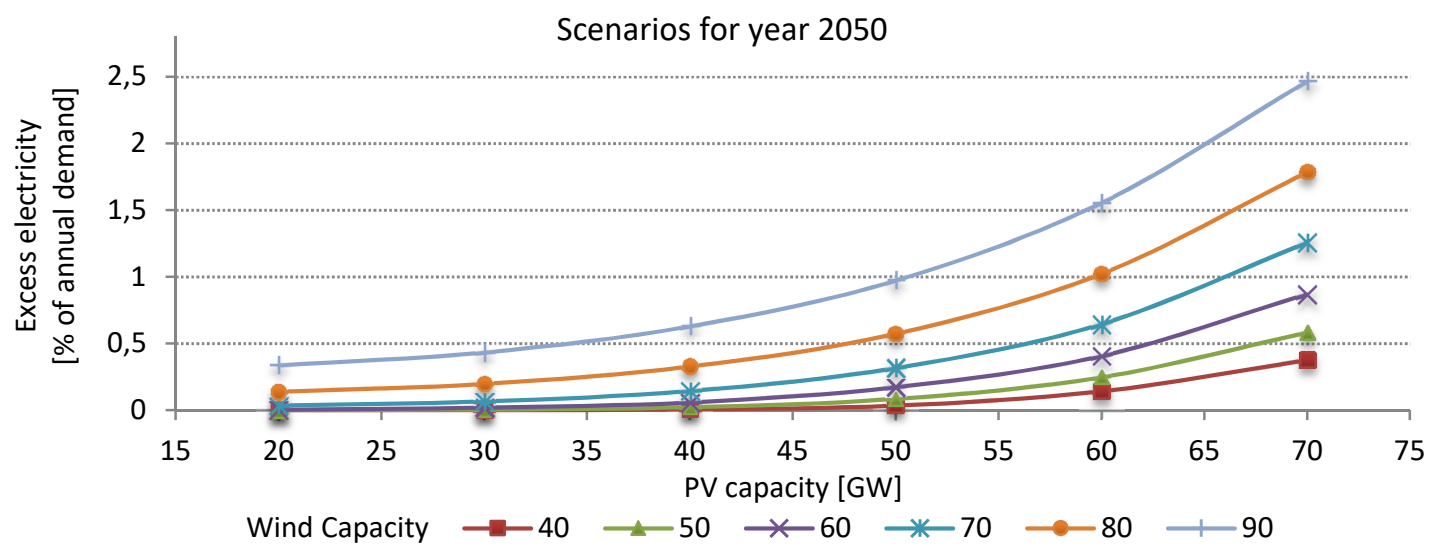

Figure 9. Excess of electricity production for 2050 scenarios

Excess of electricity production for the $75 \%$ renewable energy sources scenario. The optimal energy mix for the $75 \%$ RES scenario corresponds to a wind capacity of $100 \mathrm{GW}$ and a PV capacity of $40 \mathrm{GW}$. As seen in Figure 10 the corresponding EEP for this combination is $0.34 \%$ of the annual demand. Excess of electricity is an indicator of the systems' ability of self-regulating and integrating RES [28]. The $0.34 \%$ of EEP resulting for the optimal $75 \%$ RES scenario is not a critical value for the system considering that many storage technologies and demand flexibility strategies have not yet been included in the analyses.

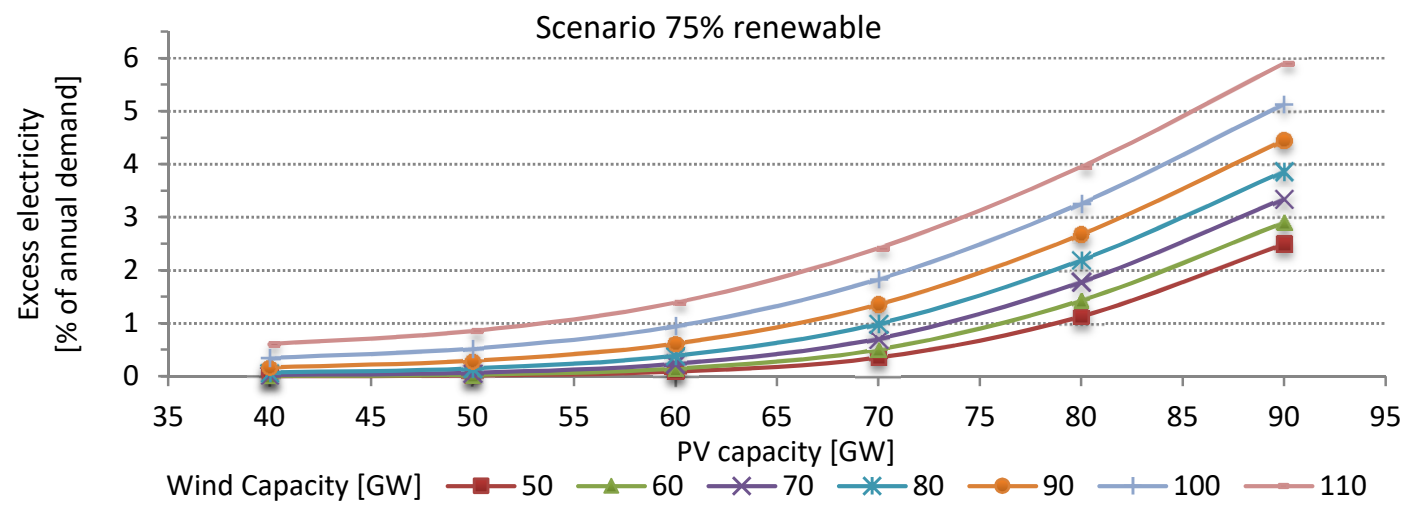

Figure 10. Excess of electricity production for the 75\% RES scenario

\section{CONCLUSIONS}

The MTMC method has been used to establish and evaluate different high-RES scenarios for transitioning the Mexican electricity system to a system where RES supplies $75 \%$ of the electricity demand. The MTMC minimizes the total installed capacity in a system combined with the accomplishment of a RES-based electricity share target. In accordance with national regulations, years 2024, 2035 and 2050 have been utilized to establish the renewables-based electricity objectives of 35\%, 40\% and 50\% respectively as well as a target of $75 \%$ of RES electricity past 2050 . 
In the scenarios, conventional technologies based on fossil fuels from the present electricity system were gradually eliminated, currently exploited RES in Mexico, hydro and geothermal power, were expanded to their maximum potentials. Several capacity combinations of bioenergy, wind, solar concentrating and PV power were investigated to obtain capacity mixes producing the specified RES electricity shares. For each bioenergy, BSW combination, the complementary NG-CC capacity necessary to make the system self-sufficient was also obtained. Several combinations reached the RES-based electricity share target for each year, defining a domain of possible solutions. By 2035 sixteen different BSW combinations produce $40 \%$ of RES electricity, by 2050 nine different BSW combinations reach the 50\% RES-electricity share objective, for the $75 \%$ RES scenario four different BSW combinations accomplish with the target. Due to the fluctuating nature of wind and PV solar energies, the resulting complementary NG-CC capacity is different for each combination in the domain of possible solutions, therefore the resulting total installed capacity in the system changes from one combination to another. For each target year, the selected combination among all possible solutions corresponded to the energy mix with the minimum total installed capacity in the system.

In every transitioning target year, the required capacity for each energy source is clearly identified, therefore it is possible to develop a national RES policy settling specific capacity targets for the different RES at defined years.

The projected demand by 2050 utilized for building the $75 \%$ RES scenario is nearly four times bigger than the current electricity demand in Mexico. The resulting total installed capacity from the $75 \%$ RES scenario is nearly five times the current installed capacity in the Mexican electricity system. Mexico possesses high RES's potentials to support such electricity system, nevertheless in this scenario NG-CC still has an important participation with a capacity of $70 \mathrm{GW}$. If the objective for the Mexican electricity system is to transform into a 100\% RES-based electricity system, the $70 \mathrm{GW}$ of NG-CC capacity must be replaced by a renewable and dispatchable energy source such as bioenergy, dammed hydro or CSP, however in the $75 \%$ RES scenario hydro and bioenergy form livestock, agricultural and municipal waste are incorporated exploiting their maximum potentials. Therefore, a more feasible way for transitioning to a $100 \%$ RES-based electricity system in Mexico can be found by setting a limit to the electricity demand growth in a lower value than the projected demand by 2050 . Also, ways to create flexible demand in the current system and gradually transform it into a smart electricity system must be explored.

Finally, the possible excess of electricity production related to the wind-PV installed capacities was evaluated. Optimal capacity combinations for each target year create scenarios where excess of electricity is not produced or is not critical as in the case of the $75 \%$ RES scenario where a value lower than $0.5 \%$ of the annual electricity demand is present.

\section{NOMENCLATURE}

\section{Abbreviations}

$\begin{array}{ll}\text { BWPV } & \text { Bioenergy, Wind and Photovoltaic Power } \\ \text { CC } & \text { Combined Cycle } \\ \text { CF } & \text { Capacity Factor } \\ \text { CSP } & \text { Concentrating Solar Power } \\ \text { DGI } & \text { Daily Global Irradiation } \\ \text { EEP } & \text { Excess of Electricity Production } \\ \text { GDP } & \text { Gross Domestic Product } \\ \text { GHG } & \text { Greenhouse Gas }\end{array}$




$\begin{array}{ll}\text { GT } & \text { Gas Turbine } \\ \text { ICE } & \text { Internal Combustion Engine } \\ \text { LWB } & \text { Livestock Waste Biogas } \\ \text { Mb } & \text { Million of oil barrels } \\ \text { MED } & \text { Maximum Electricity Demand } \\ \text { MWB } & \text { Municipal Waste Biogas } \\ \text { NG } & \text { Natural Gas } \\ \text { NG-CC } & \text { Natural Gas Combined Cycle } \\ \text { PES } & \text { Primary Energy Supply } \\ \text { PP } & \text { Condensing Power Plants } \\ \text { PV } & \text { Photovoltaic } \\ \text { RES } & \text { Renewable Energy Sources } \\ \text { TAEC } & \text { Total Annual Electricity Consumption } \\ \text { toe } & \text { tonne of oil equivalent }\end{array}$

\section{REFERENCES}

1. Petroleos Mexicanos, Statistical Yearbook 2014 (in Spanish), PEMEX, 2015.

2. International Energy Agency (IEA) - Statistics Search, http://www.iea.org/statistics/statisticssearch/, [Accessed: 26-May-2014]

3. Secretariat of Energy (SENER), National Energy Balance 2014 (in Spanish), Mexico City, Mexico, 2015.

4. EDGAR - EDGAR's Triple Contribution at COP22 - European Commission, http://edgar.jrc.ec.europa.eu/, [Accessed: 14-February-2017]

5. National Ecology Institute (INECC), Green House Gases National Inventory 1990-2010 ( $1^{\text {st }}$ ed.) (in Spanish), Mexico City, Mexico, 2013.

6. Development Program for the National Electricity System 2015-2029 (PRODESEN), Secretariat of Energy (in Spanish), 2015.

7. Vidal-Amaro, J. J., Østergaard, P. A. and Sheinbaum-Pardo, C., Optimal Energy Mix for transitioning from Fossil Fuels to Renewable Energy Sources - The Case of the Mexican Electricity System, Appl. Energy, Vol. 150, pp 80-96, 2015, https://doi.org/10.1016/j.apenergy.2015.03.133

8. Secretariat of the Interior (SEGOB), Law of Energy Transition, Official Diary of the Federation (in Spanish), pp 25-53, Mexico City, Mexico, 2015.

9. Islas, J., Manzini, F. and Martínez, M., $\mathrm{CO}_{2}$ Mitigation Costs for New Renewable Energy Capacity in the Mexican Electricity Sector using Renewable Energies, Sol. Energy, Vol. 76, No. 4, pp 499-507, 2004, https://doi.org/10.1016/j.solener.2003.06.001

10. Manzini, F., Islas, J. and Martínez, M., Reduction of Greenhouse Gases using Renewable Energies in Mexico 2025, Int. J. Hydrog. Energy, Vol. 26, No. 2, pp 145-149, 2001, https://doi.org/10.1016/S0360-3199(00)00042-2

11. Johnson, T. M., Alatorre, C., Romo, Z. and Liu, F., Low-Carbon development for Mexico, The World Bank, 2010.

12. Oropeza-Perez, I. and Østergaard, P. A., The Influence of an estimated Energy Saving due to Natural Ventilation on the Mexican Energy System, Energy, Vol. 64, No. 0, pp 1080-1091, 2014, https://doi.org/10.1016/j.energy.2013.11.009

13. Lund, H., EnergyPLAN I Advanced Energy Systems analysis Computer Model, http://www.energyplan.eu/, [Accessed: 29-October-2014]

14. Østergaard, P. A., Reviewing EnergyPLAN Simulations and Performance Indicator Applications in EnergyPLAN Simulations, Appl. Energy, Vol. 154, pp 921-933, 2015, https://doi.org/10.1016/j.apenergy.2015.05.086

15. Mahbub, M. S., Cozzini, M., Østergaard, P. A. and Alberti, F., Combining Multi-objective Evolutionary Algorithms and Descriptive Analytical modelling in 
Energy Scenario Design, Appl. Energy, Vol. 164, pp 140-151, 2016, https://doi.org/10.1016/j.apenergy.2015.11.042

16. Batas Bjelić, I., Rajaković, N., Krajačić, G. and Duić, N., Two Methods for decreasing the Flexibility Gap in National Energy Systems, Energy, Vol. 115, Part 3, pp 1701-1709, 2016, https://doi.org/10.1016/j.energy.2016.07.151

17. Connolly, D., Lund, H. and Mathiesen, B. V., Smart Energy Europe: The Technical and Economic Impact of one Potential 100\% Renewable Energy Scenario for the European Union, Renew. Sustain. Energy Rev., Vol. 60, pp 1634-1653, 2016, https://doi.org/10.1016/j.rser.2016.02.025

18. Østergaard, P. A., Mathiesen, B. V., Möller, B. and Lund, H., A Renewable Energy Scenario for Aalborg Municipality based on Low-temperature Geothermal Heat, Wind Power and Biomass, Energy, Vol. 35, No. 12, pp 4892-4901, 2010, https://doi.org/10.1016/j.energy.2010.08.041

19. Huang, Z., Yu, H., Peng, Z. and Liu, Z., Two-stage Optimization Model used for Community Energy Planning, Energy Procedia, Vol. 75, pp 2916-2921, 2015, https://doi.org/10.1016/j.egypro.2015.07.590

20. Batas Bjelić, I. and Rajaković, N., Simulation-based optimization of Sustainable National Energy Systems, Energy, Vol. 91, pp 1087-1098, 2015, https://doi.org/10.1016/j.energy.2015.09.006

21. Berkeley Lab, Genopt, http://simulationresearch.lbl.gov/GO/index.html, [Accessed: 02-March-2017]

22. Kuravi, S., Trahan, J., Goswami, D. Y., Rahman, M. M. and Stefanakos, E. K., Thermal Energy Storage Technologies and Systems for Concentrating Solar Power Plants, Prog. Energy Combust. Sci., Vol. 39, No. 4, pp 285-319, 2013, https://doi.org/10.1016/j.pecs.2013.02.001

23. International Energy Agency (IEA), Publication - Technology Roadmap: Concentrating Solar Power, 2010.

24. Peterseim, J. H., Hellwig, U., Tadros, A. and White, S., Hybridisation optimization of concentrating Solar Thermal and Biomass Power Generation Facilities, Sol. Energy, Vol. 99, pp 203-214, 2014, https://doi.org/10.1016/j.solener.2013.10.041

25. Institute of Electrical Research (IIE), Renewable Resources Explorer (SIGER) (in Spanish), 2016, http://sag01.iie.org.mx/SIGER/, [Accessed: 02-March-2017]

26. EnergyNet, Technology Data For Energy Plants, Danish Energy Agency, 2012.

27. Baharoon, D. A., Rahman, H. A., Omar, W. Z. W. and Fadhl, S. O., Historical development of concentrating Solar Power Technologies to generate Clean Electricity Efficiently - A Review, Renew. Sustain. Energy Rev., Vol. 41, pp 996-1027, 2015, https://doi.org/10.1016/j.rser.2014.09.008

28. Lund, H. and Willet, K., Chapter 5, Large-Scale Integration of Renewable Energy, Renewable Energy Systems (2 ${ }^{\text {nd }}$ ed.), Oxford: Academic Press, pp 79-129. 